\title{
Fluorescent CD4 probe for potential HIV-1 gp120 protein detection
}

\author{
Zhongjie Wang, Poulami Talukder, Sidney M. Hecht, Shengxi Chen*
}

Center for BioEnergetics, Biodesign Institute, and Department of Chemistry and Biochemistry, Arizona State University, 1001 South McAllister Avenue, Tempe, Arizona 85287, USA

* Corresponding author. Tel: +1-480-727-0388. Fax: +1-480-965-0038.

E-mail address: $\underline{\text { shengxi.chen.1@asu.edu }}$

Keywords: fluorescent CD4, acridon-2-ylalanine, FRET, gp120, HIV detection

Abbreviations: HIV-1, human immunodeficiency virus type 1; mD1, mutant CD4 domain 1; FRET, Förster resonance energy transfer; Acd, acridon-2-ylalanine; EB, Evans blue; PET, photoinduced electron transfer. 


\begin{abstract}
A fluorescently modified CD4 domain $1(\mathrm{mD} 1)$ protein has been designed and elaborated in an in vitro expression system. This fluorescent probe contains a Förster resonance energy transfer (FRET) pair, which uses a tryptophan residue as the fluorescence donor and an acridon-2ylalanine (Acd) as the acceptor. When excited at $260 \mathrm{~nm}$, energy was transferred from tryptophan to the Acd residue of $\mathrm{mD1}$, and emitted fluorescence at $420 \mathrm{~nm}$. This fluoresence was quenched after Evans blue (EB) inhibitor or HIV-1 gp120 protein binding, presumably as a consequence of changes in the distance and dipole orientation between the donor and acceptor; the emission intensity at $420 \mathrm{~nm}$ decreased in a concentration-dependent fashion. This fluorescent CD4 probe could be developed into a novel tool for HIV-1 gp120 protein detection. It also could be used to screen small molecules that inhibit the gp120-CD4 interaction.
\end{abstract}


As the initial binding envelope protein for viral entry, HIV-1 gp120 is an attractive target for developing novel methods of HIV-1 detection. ${ }^{1-3}$ The entry of HIV-1 into host immune cells begins with the specific binding of gp120 envelope protein to cellular CD4 receptors on the surface of macrophages and T cells. ${ }^{4}$ Although the surface of gp120 is extensively glycosylated to avoid binding by antibodies, the conserved CD4 binding domain remains intact. ${ }^{5}$ The X-ray crystallographic structure of the CD4-gp120 complex shows a large interacting surface between the CD4 domain 1 (involving 22 amino acid residues) and HIV-1 gp120 (involving 26 amino acid residues) ${ }^{6,7}$ This large interacting surface results in a high specificity and affinity of CD4gp120 interaction. In a previous study, a mutant CD4 domain $1(\mathrm{mD} 1.2,12 \mathrm{KDa})$ protein showed about 50-fold stronger binding affinity for HIV-1 gp120 than the soluble CD4 (sCD4) receptor. ${ }^{8}$ The small size, favorable solubility and strong affinity of this mD1.2 protein makes it an ideal probe to detect HIV-1 gp120 protein.

Förster resonance energy transfer (FRET) has been used extensively to study the structure and binding of proteins. ${ }^{9-11}$ As a fluorescence acceptor, the amino acid acridon-2-ylalanine (Acd) is an attractive fluorophore because of its high quantum yield, high photostability and small size. ${ }^{12}$ Its small size enables it to minimally perturb the folding of proteins in which it is incorporated. In this study, we prepared a fluorescent $\mathrm{mD} 1$ protein sensor that can specifically bind to the conserved domain of HIV gp120 protein. This fluorescent probe contains an acridon-2-ylalanine and a tryptophan that form a FRET pair. Once bound to gp120 protein, the fluorescence intensity of the sensor is decreased. Thus, this method could be used to detect the gp120 protein of HIV virus directly. It does not require any response from the human immune system which can take several weeks following infection, thus potentially enabling the detection of HIV infection at an early stage. 
The mD1.2 plasmid containing CD4 domain 1 gene under the control of a lac promoter was obtained as a gift from Dr. Dimiter S. Dimitrov. The mD1.2 plasmid was digested using restriction endonuclease SfiI (New England BioLabs, USA) to release the mD1.2 gene. The gene encoding the mD1.2 protein was elongated using the Taq DNA polymerase (New England BioLabs, USA) and two synthesized oligonucleotides (IDT, USA): a forward oligonucleotide (5'-GGA TAT ACA TAT GAC CGT GGC CCA GGC GGC CAA GAA GGT GGT GTA CG-3') containing restriction site for NdeI (New England BioLabs, USA) at the N-terminus of the mD1.2 gene, and a reverse oligonucleotide (5'-CGC GGA TCC TTA CAT CAT GCC GTG ATG GTG GTG ATG GTG GCC GGC CTG GCC GCC TAC CAC TAC CAG-3') containing a hexahistidine casette and a restriction site for BamHI (New England BioLabs, USA) at the Cterminus of the mD1.2 gene. After digestion using NdeI and BamHI, the modified CD4 domain 1 (mD1) gene was inserted into a pET16 vector.

Site-directed mutagenesis of position 28 of mD1 was carried out using a primer 5'-CAG AAG

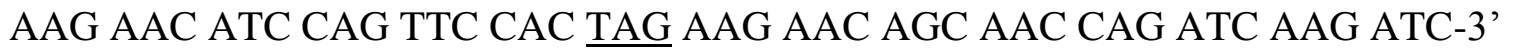
following a reported procedure. ${ }^{13}$

The acridon-2-ylalanyl-tRNA $\mathrm{CUA}_{\text {A }}$ was prepared following our reported procedure. ${ }^{14}$ The in vitro expression mixture (600 $\mu \mathrm{L}$ total volume) contained $60 \mu \mathrm{g}$ of modified $\mathrm{mD} 1$ (TAG at position 28) plasmid DNA, $300 \mu \mathrm{L}$ of premix (35 mM Tris-acetate, $\mathrm{pH} 7.0$, containing $190 \mathrm{mM}$ potassium glutamate, $30 \mathrm{mM}$ ammonium acetate, $2.0 \mathrm{mM}$ dithiothreitol, $11 \mathrm{mM}$ magnesium acetate, $20 \mathrm{mM}$ phospho(enol)pyruvate, $0.8 \mathrm{mg} / \mathrm{mL}$ of $E$. coli $\mathrm{tRNA}, 0.8 \mathrm{mM}$ IPTG, $20 \mathrm{mM}$ ATP and GTP, $5 \mathrm{mM} \mathrm{CTP}$ and UTP and $4 \mathrm{mM}$ cAMP), $100 \mu \mathrm{M}$ of each of the 20 amino acids, $60 \mu \mathrm{Ci}$ of $\left[{ }^{35} \mathrm{~S}\right]$-L-methionine, $10 \mu \mathrm{g} / \mu \mathrm{L}$ rifampicin, $180 \mu \mathrm{g}$ of aminoacylated $\mathrm{tRNA} \mathrm{CUA}_{\mathrm{A}}$ and $180 \mu \mathrm{L}$ of 
S-30 extract from E. coli strain BL21(DE3). ${ }^{15,16}$ The reaction mixture was incubated at $30{ }^{\circ} \mathrm{C}$ for 45 min. Plasmid DNA containing the gene for wild-type mD1 was used as a positive control, and an abbreviated tRNA (tRNA- $\mathrm{C}_{\mathrm{OH}}$ ) lacking any amino acid was used as the negative control. An aliquot containing $2 \mu \mathrm{L}$ of reaction mixture was removed, treated with $2 \mu \mathrm{L}$ of loading buffer and heated at $90{ }^{\circ} \mathrm{C}$ for $2 \mathrm{~min}$. The sample was analyzed by $15 \%$ SDS-PAGE at $100 \mathrm{~V}$ for $2 \mathrm{~h}$.

The wild-type and modified $\mathrm{mD} 1 \mathrm{~s}$ containing a $\mathrm{C}$-terminal hexahistidine fusion peptide were purified by Ni-NTA chromatography. The in vitro translation reaction mixture $(600 \mu \mathrm{L})$ was diluted with $1800 \mu \mathrm{L}$ of $50 \mathrm{mM}$ Tris- $\mathrm{HCl}, \mathrm{pH} 8.0$, containing $300 \mathrm{mM} \mathrm{NaCl}$ and $10 \mathrm{mM}$ imidazole, and mixed gently with $150 \mu \mathrm{L}$ of $50 \%$ slurry of Ni-NTA resin at $4{ }^{\circ} \mathrm{C}$ for $1 \mathrm{~h}$. Then the mixture was applied to a column and washed with $800 \mu \mathrm{L}$ of $50 \mathrm{mM}$ Tris- $\mathrm{HCl}, \mathrm{pH} 8.0$, containing $300 \mathrm{mM} \mathrm{NaCl}$ and $10 \mathrm{mM}$ imidazole. Finally, the $\mathrm{mD} 1$ protein was eluted four times with $150-\mu \mathrm{L}$ portions of $50 \mathrm{mM}$ Tris- $\mathrm{HCl}, \mathrm{pH} 8.0$, containing $300 \mathrm{mM} \mathrm{NaCl}$ and $150 \mathrm{mM}$ imidazole. Aliquots of each fraction were analyzed by 15\% SDS-PAGE. The eluates containing $\mathrm{mD} 1$ protein were combined and loaded on a Sephadex-G25 column $(10 \times 0.5 \mathrm{~cm})$ and eluted ten times with $150 \mu \mathrm{L}$ of $50 \mathrm{mM}$ Tris-HCl, $\mathrm{pH}$ 8.0. Aliquots of each fraction were analyzed again by $15 \%$ SDS-PAGE.

The fluorescence spectra of modified $\mathrm{mD} 1$ containing acridon-2-ylalanine at position 28 was measured using a Varian Cary Eclipse Fluorescence Spectrophotometer with the excitation slit set at $10 \mathrm{~nm}$ and emission slit at $10 \mathrm{~nm}$. The emission spectra of $50 \mu \mathrm{L} 1.0 \mu \mathrm{M}$ modified mD1 protein sample was recorded at $\mathrm{pH} 8.0$ following excitation at $260 \mathrm{~nm}$. To $50 \mu \mathrm{L}$ of $1.0 \mu \mathrm{M}$ modified mD1 protein samples was added 2.0 - 10.0 $\mu$ M Evans blue (EB) (MP Biomedicals, 
USA) or $0.2-1.0 \mu \mathrm{M}$ HIV-1 gp120 (Fitzgerald Industries International Inc, USA). After incubation at room temperature for $10 \mathrm{~min}$, the emission spectra of modified $\mathrm{mD} 1$ protein samples were recorded following excitation at $260 \mathrm{~nm}$.

Human membrane protein CD4 contains four immunoglobulin domains ( $\mathrm{D}_{1}$ to $\left.\mathrm{D}_{4}\right)$ that are found on the extracellular surface of immune cells such as T cells, macrophages, monocytes and dendritic cells. ${ }^{17}$ These four domains are responsible for binding to different regulatory molecules in human blood. For HIV-1 infection, the binding of domain 1 (D1) of CD4 on T cells to HIV-1 gp120 protein initiates viral entry. ${ }^{18}$ Recently, Chen and co-workers have designed and screened several D1 mutant libraries. They found a mutant CD4 domain $1(\mathrm{mD} 1.2)$ protein having better solubility (2-fold) and much stronger binding ability to HIV-1 gp120 (50-fold) than the soluble $\mathrm{CD} 4(\mathrm{sCD} 4)$ receptor. ${ }^{8}$ The properties of this $\mathrm{mD} 1.2$ protein were used to develop a fluorescent probe to detect the HIV-1 gp120 protein in this study.

The mD1.2 gene obtained from Dr. Dimiter S. Dimitrov was inserted into a pComb3X vector. The transcription and translation of pComb3X plasmid in Escherichia coli cells is inhibited by rifampicin, which binds to bacterial DNA-dependent RNA polymerase. ${ }^{19}$ However, in the E. coli strain BL21 (DE3) expression system, there is overexpressed T7 polymerase that only transcribes the $\mathrm{mD} 1$ gene under the control of a T7 promoter. ${ }^{20}$ Thus, the $\mathrm{mD} 1.2$ and a Cterminal hexa-histidine gene were inserted into a pET16 vector to obtain the pET16-mD1 plasmid, which contains a T7 promoter to enable expression in the E. coli strain BL21 (DE3) expression system (Scheme 1). To site-specifically incorporate the fluorescent amino acid into the $\mathrm{mD} 1$, a nonsense codon (TAG) was introduced at position 28 of $\mathrm{mD} 1$ following a reported procedure. $^{13,21}$ 
As shown in Scheme 1, the $N$-NVOC protected acridon-2-ylalanyl-pdCpAs was ligated to a suppressor tRNA ${ }_{\mathrm{CUA}}$ lacking the 3'-terminal CpA moiety by the use of T4 RNA ligase. ${ }^{22}$ The $^{2}$ ligation afforded full length $N$-NVOC-acridon-2-ylalanyl-tRNA $\mathrm{CUA}_{\mathrm{A}}$. The NVOC group was removed using a high intensity mercury-xenon light to obtain the activated tRNA. ${ }^{23}$ Then the pET16-mD1 plasmid containing a nonsense codon (TAG) at position 28 was employed in a cell free translation system in the presence of acridon-2-ylalanyl-tRNA $A_{C U A}$. Since nonsense UAG codon can only be decoded by the activated $\mathrm{tRNA}_{\mathrm{CUA}}$, the expression afforded a modified $\mathrm{mD} 1$ protein with the acridon-2-ylalanine at position $28 .{ }^{14}$ As shown in Fig. 1, the suppression yield of modified protein was $15 \%$ compared to wild-type $\mathrm{mD} 1$. The translated $\mathrm{mD} 1$ protein included a hexahistidine fusion peptide at the C-terminus, which facilitates purification. Following purification with Ni-NTA, wild-type and modified mD1 proteins were obtained in a solution containing $150 \mathrm{mM}$ imidazole, which affects the fluorescence properties of modified $\mathrm{mD} 1$ protein. To remove the imidazole, a Sephadex-G25 column was used to obtain the desired purified proteins.

Acridon-2-ylalanine has been incorporated into a few proteins to study their conformation changes as a FRET acceptor with minimal perturbation to protein folding. ${ }^{12,14}$ The Acd absorption spectrum overlaps with the tail of the tryptophan (Trp) emission spectrum. Thus, it can form a FRET pair with Trp, with a Förster radius $\left(R_{0}\right)$ of $23 \AA{ }^{12}$ However, in a steady state fluorescence Stern-Volmer titration assay, Trp and tyrosine (Tyr) can significantly quench the fluorescence of Acd through a photoinduced electron transfer (PET) mechanism when their distance is less than $15 \AA .^{12}$ These opposing effects of Trp on the fluorescence emission of Acd complicate the use of this fluorophore for the study protein conformation changes, but potentially 
may provide multiple mechanisms to monitor protein-protein interactions. Accordingly we began our study by exploring the ability of Trp and Acd to form a FRET pair in the $\mathrm{mD} 1$ protein.

The mD1 protein contains only two tryptophans (Trp28 and Trp62), which are $10.4 \AA$ apart (PBD 1CDJ). ${ }^{24}$ We replaced Trp28 with Acd as the fluorescence acceptor, and used Trp62 as the fluorescence donor. When excited at 250-270 nm, there was an efficient FRET between Acd28 and Trp62 with the emission maximum at $420 \mathrm{~nm}$ (Fig. S1). However, when excited at the absorbance maximum of free tryptophan $(280 \mathrm{~nm})$, the FRET signal was significantly diminished. Even when excited at the absorbance maximum of free Acd $(385 \mathrm{~nm})$, the fluorescence emission was quenched. To explore the possible effect of other amino acid residues, such as Tyr82, we switched the positions of this FRET pair by incorporation of Acd into position 62. The FRET signal between Trp28 and Acd62 was exactly same as the FRET obtained from Trp62 and Acd28 (Fig. S2). The distance from Tyr82 to Trp28 is $6.0 \AA$, and to Trp62 is $17.5 \AA$ (PBD 1GC1). ${ }^{6}$ The dramatically different distances between Tyr82 and Acd28/Acd62 did not change the fluorescence properties of Acd. This suggested that the Tyr residue did not affect energy transfer between Trp and Acd in the modified mD1 proteins. That the same FRET signal was observed for Trp28-Acd62 and Trp62-Acd28 also suggested that the Acd residue did not significantly perturb the structure of $\mathrm{mD} 1$ protein when it was located at position 28 or 62 .

We suggest that the FRET enhancement observed when the modified $\mathrm{mD} 1$ protein containing Acd at position 28 was excited at $260 \mathrm{~nm}$ (Fig. S1), may differ from the diminution in fluorescence observed following excitation at $280 \mathrm{~nm}$ due to the excitation of different transitions in $\operatorname{Trp}$ (i.e. the ${ }^{1} \mathrm{~L}_{\mathrm{a}}$ and ${ }^{1} \mathrm{~L}_{\mathrm{b}}$ transitions). ${ }^{25}$ 
To study the conformational change of $\mathrm{mD} 1$ protein using this FRET pair, the CD4 inhibitor Evans blue (EB) was added to the $\mathrm{mD} 1$ solution. ${ }^{26}$ As shown in Fig. 2, when $1.0 \mu \mathrm{M}$ mD1 was treated with excess EB, the fluorescence emission intensity at $420 \mathrm{~nm}$ decreased in a concentration-dependent fashion. At the same time, the intensity of the emission at $345 \mathrm{~nm}$ also decreased in a concentration-dependent fashion. This was presumably due to the binding of EB to $\mathrm{mD} 1$ protein, changing the structure of $\mathrm{mD} 1$ in a fashion that perturbed the distance between Acd28 and Trp62, or the orientation of the transition dipole moments of the donor and acceptor, thus reducing the observed energy transfer.

Finally, one modified mD1 protein (Acd28) was used to detect HIV-1 gp120 binding by monitoring changes in FRET signal intensity. As shown in Fig. 3, the FRET signal was decreased in a concentration-dependent fashion when $0.2-1.0$ equivalent of gp120 protein was added. Comparing the X-ray crystallographic structure of the CD4-gp120 complex and CD4 protein, the Trp28 residue shifted only slightly (Fig. S3). ${ }^{6,24}$ However, the Trp62 residue in the CD4-gp120 complex moved by $\sim 1.1 \AA$ and was rotated by about $5^{\circ}$. For the modified mD1 protein containing Acd28, the analogous movement of Trp62 would change both the distance between Trp28 and Acd62, and the orientation of their transition dipole moments, consistent with the observed decrease in fluorescence emission intensity resulting from binding to HIV-1 gp120. In this study, the possibility of a decrease in fluorescence intensity due to gp120 protein interactions via a PET mechanism can be excluded, since all of the tryptophan and tyrosine residues of HIV-1 gp120 protein are quite distant from the Acd28 residue of modified mD1 protein (> $22 \AA$, PBD $1 \mathrm{GC} 1)$. 
In summary, a fluorescent mD1 probe containing a FRET pair was designed and expressed. When excited at $260 \mathrm{~nm}$, energy was transferred from Trp62 to Acd28 and emitted fluorescence at $420 \mathrm{~nm}$. This FRET signal was used to study the specific binding of $\mathrm{mD} 1$ protein to an inhibitor (EB) and to its target protein HIV-1 gp120 in aqueous solution. A change in FRET signal intensity could be detected unambiguously in the presence of 0.2 equivalent of gp120. While the sensitivity of the current assay is less than that required to detect very limited numbers of copies of gp120, single molecule methods could in principle be employed to significantly enhance sensitivity.

\section{Acknowledgements}

We thank Dr. Dimiter S. Dimitrov for the gift of the mD1.2 plasmid. We also appreciate the assistance provided by Dr. Weizao Chen in the Center for Cancer Research of the National Cancer Institute during the construction of the new plasmid. We thank Prof. Marcia Levitus, Arizona State University, for helpful discussions during the course of this work. This work was performed with the support of Bill \& Melinda Gates Foundation through the Grant Challenges Explorations initiative (Grant No. OPP1061337). 


\section{References}

1. Gilbert, M.; Kirihara, J.; Mills, J. J. Clin. Microbiol. 1991, 29, 142.

2. Rychert, J.; Strick, D.; Bazner, S.; Robinson, J.; Rosenberg, E. AIDS Res. Hum. Retroviruses 2010, 26, 1139.

3. Lines, J. A.; Yu, Z.; Dedkova, L. M.; Chen, S. Biochem. Biophys. Res. Commun. 2014, 443, 308.

4. Wyatt, R.; Sodroski, J. Science 1998, 280, 1884.

5. Starcich, B. R.; Hahn, B. H.; Shaw, G. M.; McNeely, P. D.; Modrow, S.; Wolf, H.; Parks, E. S.; Parks, W. P.; Josephs, S. F.; Gallo, R. C.; Wong-Staal, F. Cell 1986, 45, 637.

6. Kwong, P. D.; Wyatt, R.; Robinson, J.; Sweet, R. W.; Sodroski, J.; Hendrickson, W. A. Nature 1998, 393, 648.

7. Moebius, U.; Clayton, L. K.; Abraham, S.; Harrison, S. C.; Reinherz, E. L. J. Exp. Med. 1992, 176, 507.

8. Chen, W.; Feng, Y.; Gong, R.; Zhu, Z.; Wang, Y.; Zhao, Q.; Dimitrov, D. S. J. Virol. 2011, 85, 9395.

9. Chen, S.; Fahmi, N. E.; Wang, L.; Bhattacharya, C.; Benkovic, S. J.; Hecht, S. M. J. Am. Chem. Soc. 2013, 135, 12924.

10. Chen, S.; Fahmi, N. E.; Bhattacharya, C.; Wang, L.; Jin, Y.; Benkovic, S. J.; Hecht, S. M. Biochemistry 2013, 52, 8580 .

11. Periasamy, A. J. Biomed. Opt. 2001, 6, 287.

12. Speight, L. C.; Muthusamy, A. K.; Goldberg, J. M.; Warner, J. B.; Wissner, R. F.; Willi, T. S.; Woodman, B. F.; Mehl, R. A.; Petersson, E. J. J. Am. Chem. Soc. 2013, 135, 18806.

13. Sawano, A.; Miyawaki, A. Nucleic Acids Res. 2000, 28, E78. 
14. Talukder, P.; Chen, S.; Liu, C. T.; Baldwin, E. A.; Benkovic, S. J.; Hecht, S. M. Bioorg. Med. Chem. 2014, 22, 5924.

15. Chen, S.; Wang, L.; Fahmi, N. E.; Benkovic, S. J.; Hecht, S. M. J. Am. Chem. Soc. 2012, $134,18883$.

16. Chen, S.; Zhang, Y.; Hecht, S. M. Biochemistry 2011, 50, 9340.

17. Maddon, P. J.; Molineaux, S. M.; Maddon, D. E.; Zimmerman, K. A.; Godfrey, M.; Alt, F. W.; Chess, L.; Axel, R. Proc. Natl. Acad. Sci. U.S.A. 1987, 84, 9155.

18. Liu, J.; Bartesaghi, A.; Borgnia, M. J.; Sapiro, G.; Subramaniam, S. Nature 2008, 455, 109.

19. White, R. J.; Lancini, G. C.; Silvestri, L. G. J. Bacteriol. 1971, 108, 737.

20. Pratt, J. M. Transcription and Translation: A Practical Approach; IRL Press: Oxford, 1984.

21. Yu, X.; Talukder, P.; Bhattacharya, C.; Fahmi, N. E.; Lines, J. A.; Dedkova, L. M.; LaBaer, J.; Hecht, S. M.; Chen, S. Bioorg. Med. Chem. Lett. 2014, 24, 5699.

22. Karginov, V. A.; Mamaev, S. V.; An, H.; Van Cleve, M. D.; Hecht, S. M.; Komatsoulis, G. A.; Abelson, J. N. J. Am. Chem. Soc. 1997, 119, 8166.

23. Mendel, D.; Cornish, V. W.; Schultz, P. G. Annu. Rev. Biophys. Biomol. Struct. 1995, 24, 435.

24. Wu, H.; Myszka, D. G.; Tendian, S. W.; Brouillette, C. G.; Sweet, R. W.; Chaiken, I. M.; Hendrickson, W. A. Proc. Natl. Acad. Sci. U.S.A. 1996, 93, 15030.

25. Lakowicz, J. R. Principles of fluorescence spectroscopy. Springer: New York, 2006. 
26. Weaver, J. L.; Gergely, P.; Pine, P. S.; Patzer, E.; Aszalos, A. AIDS Res. Hum. Retroviruses 1990, 6, 1125. 


\section{Figure Lengends}

Scheme 1. Strategy Employed for the Incorporation Acridon-2-ylalanine of into mD1 at Position 28 and Binding with HIV-1 gp120 Protein.

Figure 1. Autoradiogram of a 15\% SDS-polyacrylamide gel (100 V, 2 h) illustrating the incorporation of acridon-2-ylalanine into position 28 of $\mathrm{mD} 1$. Lane 1, wild-type $\mathrm{mD} 1$ expression; lane 2, modified mD1 DNA in the presence of an abbreviated suppressor tRNA $\mathrm{CUA}_{\mathrm{O}}-\mathrm{C}_{\mathrm{OH}}$; lane 3 , incorporation of acridon-2-ylalanine. Phosphorimager analysis was performed using an Amersham Biosciences Storm 820 equipped with ImageQuant version 5.2 software from Molecular Dynamics.

Figure 2. Fluorescence of $1 \mu \mathrm{M}$ wild-type and modified mD1 (Acd28) protein in the presence of the inhibitor Evans blue (EB). The spectra were recorded following excitation at $260 \mathrm{~nm}$.

Figure 3. Fluorescence of $1 \mu \mathrm{M}$ modified $\mathrm{mD} 1$ protein $(\mathrm{Acd} 28)$ in the prescence of different concentrations of HIV-1 gp120. The spectra were recorded following excitation at $260 \mathrm{~nm}$. 


\section{Scheme 1.}
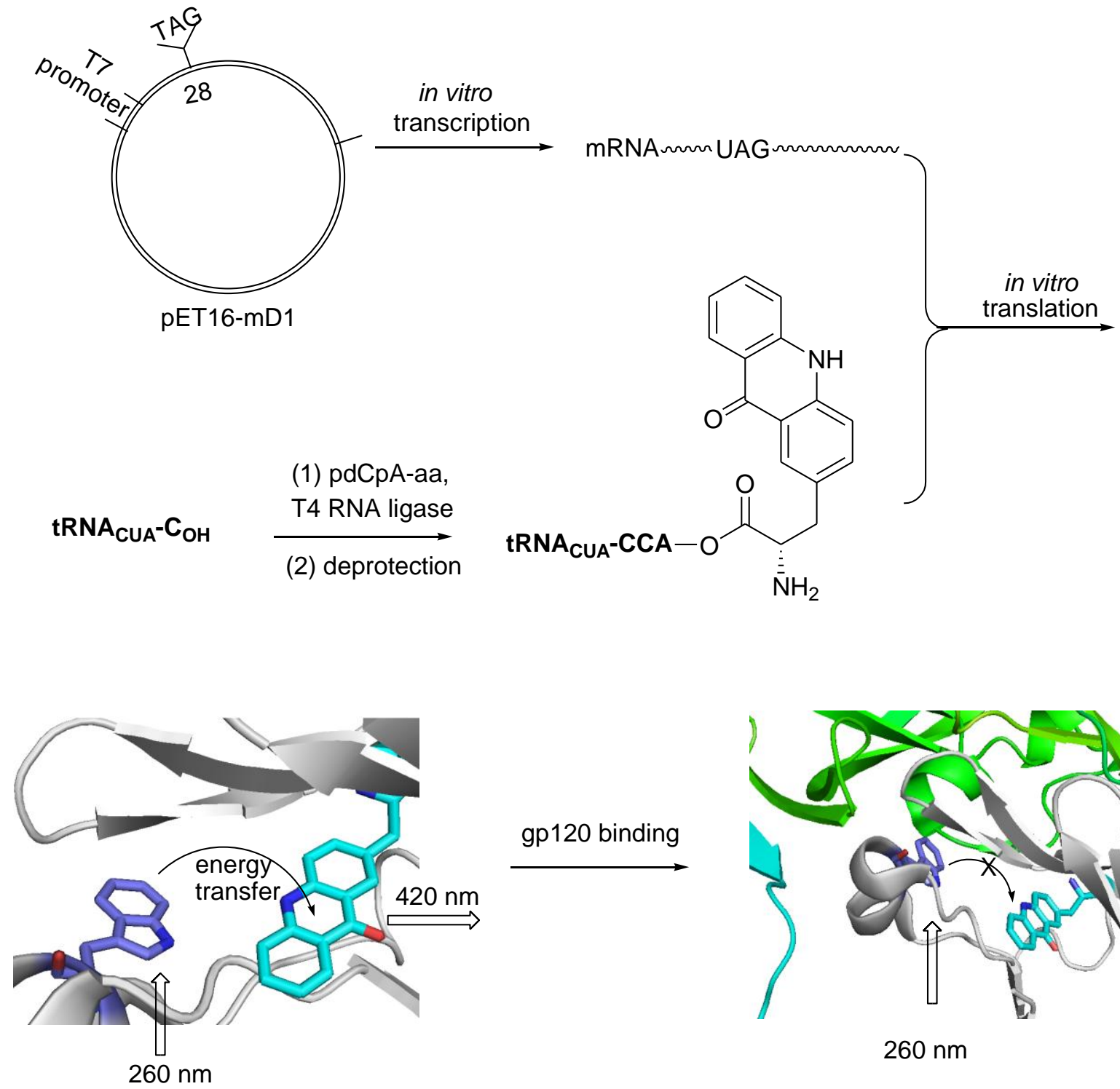

gp120 binding

modified mD1

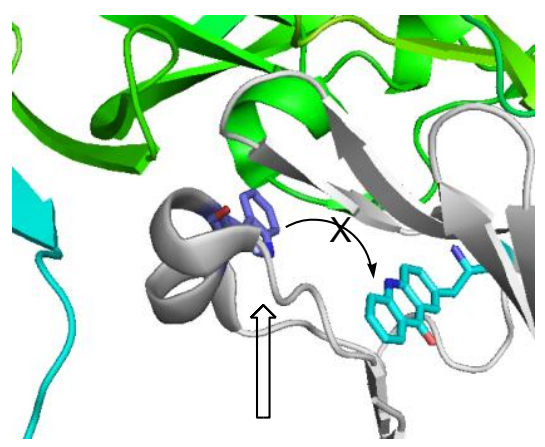

$260 \mathrm{~nm}$

modified mD1 - gp120 
Figure 1.

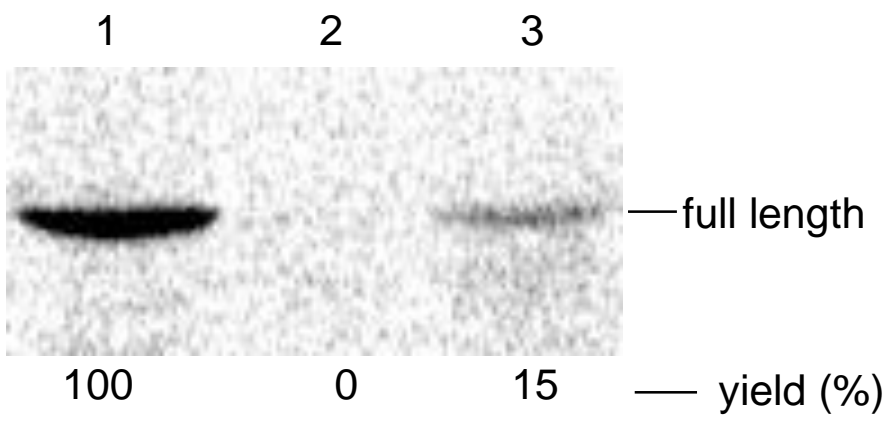


Figure 2.

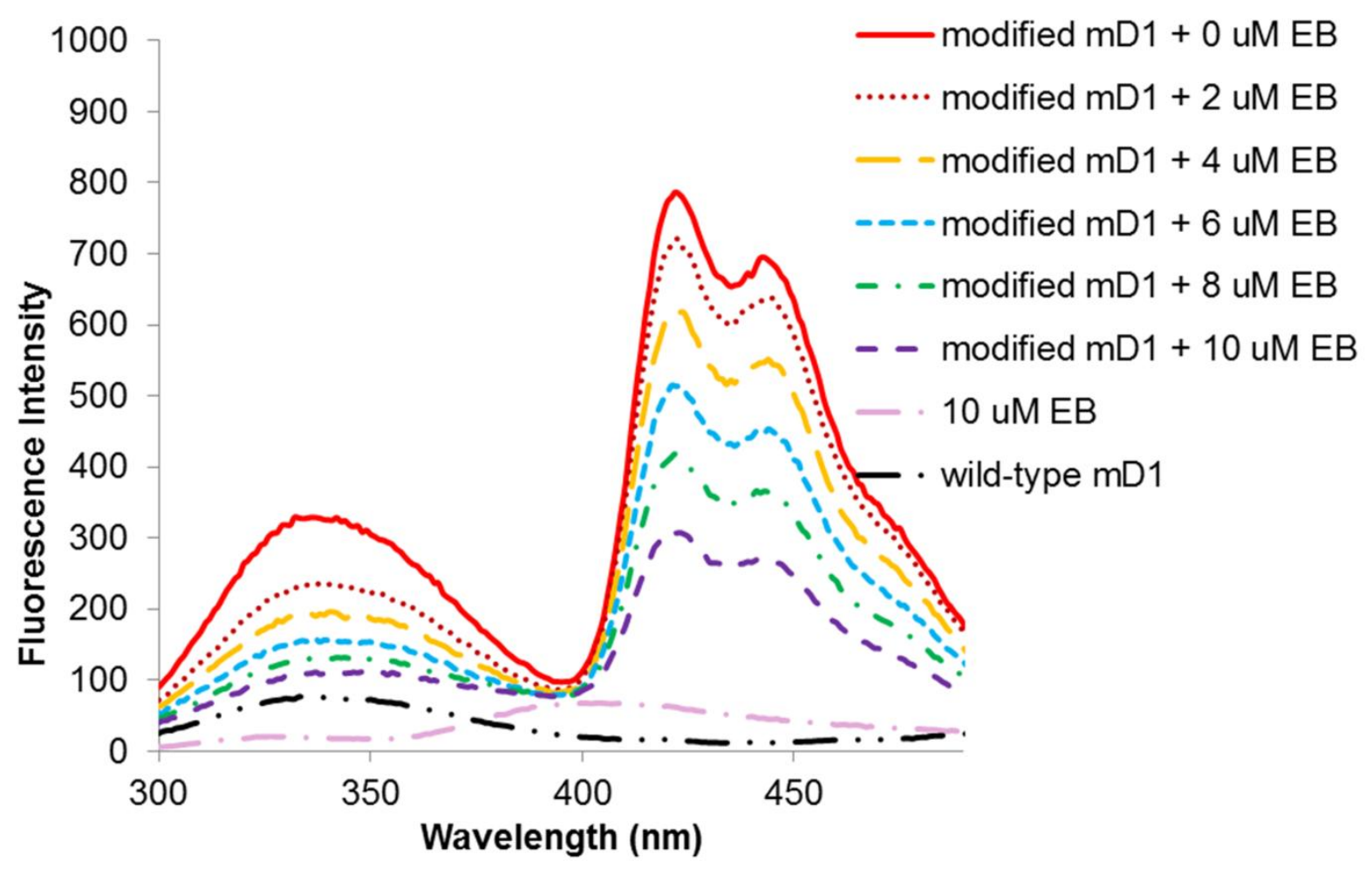


Figure 3.

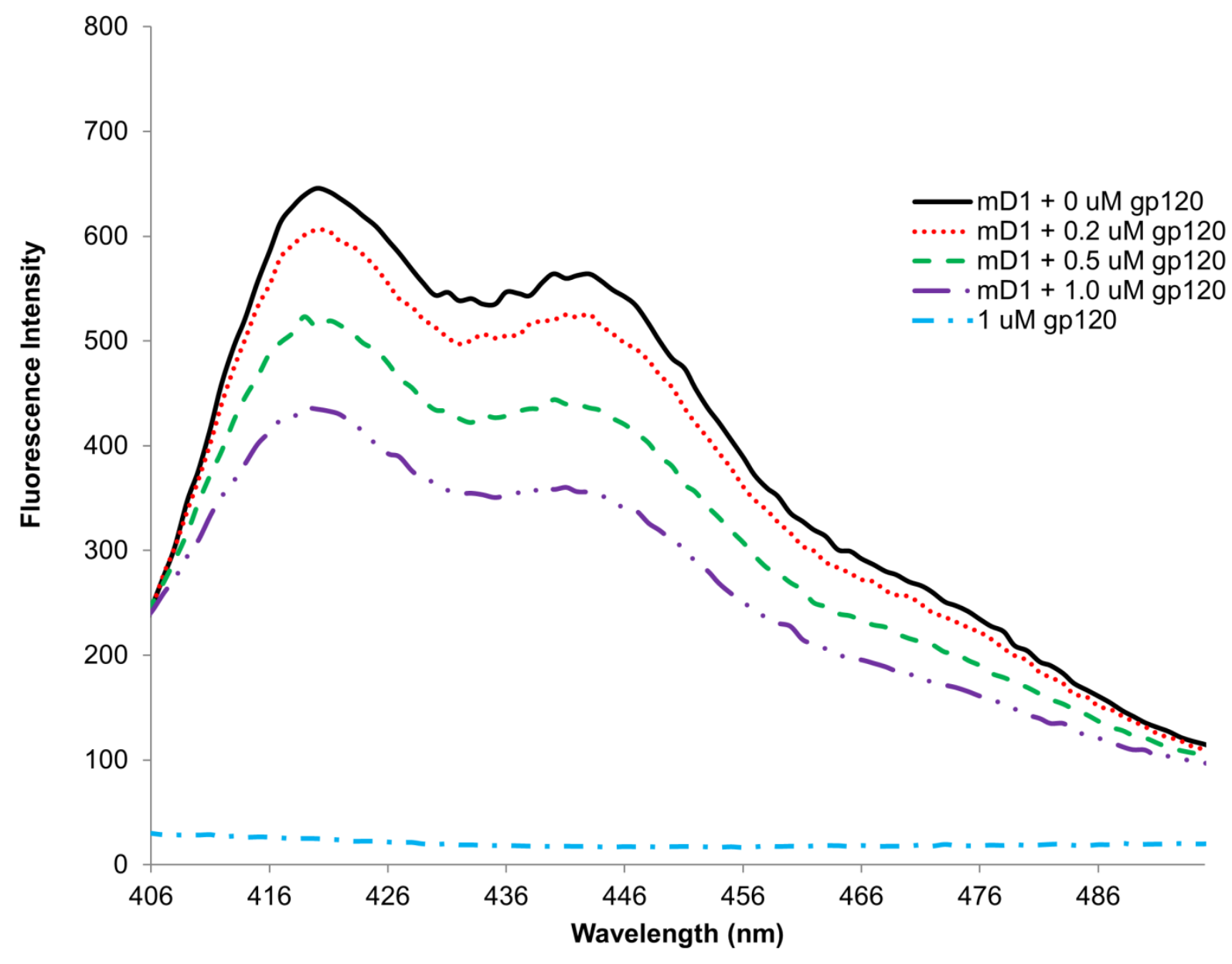




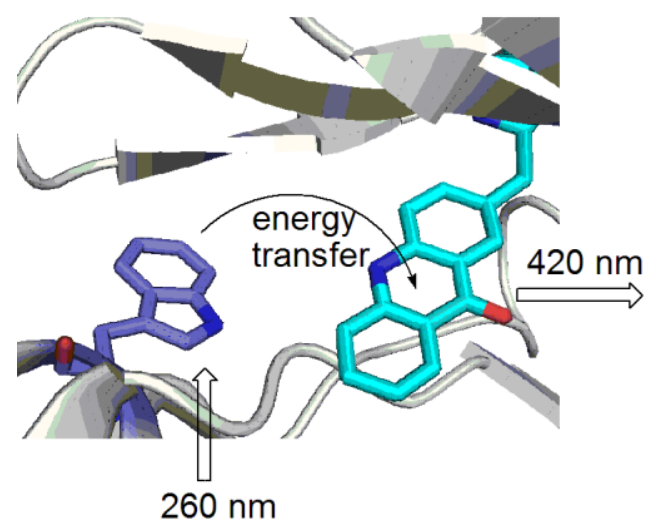

gp120 binding

modified mD1

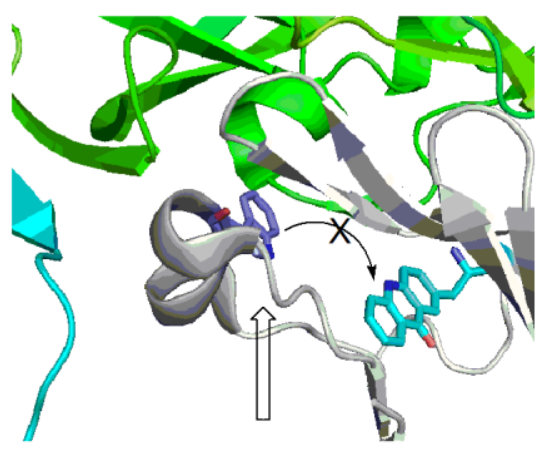

$260 \mathrm{~nm}$

modified mD1 - gp120 